\title{
Análise da produção científica da enfermagem acerca do cuidado familiar no domicílio (2000-2005)
}

\author{
Analysis of nursing scientific production about family care at home (2000-2005)
}

Análisis de la producción cientifica de enfermería referente al cuidado familiar en el domicilio (2000-2005)

\author{
Edilma Gomes Rocha', Ana Larissa Gomes Machado', \\ Ana Virgínia de Melo Fialho', Thereza Magalhães Moreira' \\ 'Universidade Estadual do Ceará. Curso de Mestrado em Cuidados Clínicos em Saúde. Fortaleza, CE
}

Submissão: 26/04/2007

Aprovação: 03/03/2008

\section{RESUMO}

Objetivou-se analisar a produção científica da enfermagem acerca da temática cuidado familiar no domicílio, por meio do levantamento bibliográfico em endereços eletrônicos de periódicos de enfermagem QUALIS "C" internacional e no acervo de duas universidades cearenses, relativos ao período de 2000 a 2005. Foram analisados 33 artigos. Os achados permitiram a constatação do maior interesse de alunos de pós-graduação pela temática; de que $85 \%$ dos trabalhos eram do Sudeste do País e da predominância de estudos qualitativos (26). Constatamos também 29 participações de membros familiares em atividades de cuidado. Em conclusão, a enfermagem tem inserido o cuidado familiar no domicílio em suas pesquisas, porém ainda incipientemente, retratando sua inibida contribuição para o preparo desses familiares para o cuidado na prática.

Descritores: Pesquisa; Enfermagem; Família.

ABSTRACT

This study aimed to analyze the nursing's scientific production about the thematic family care at home, through bibliographic research in electronic data bases in wihch nursing journals with QUALIS "C" international evaluation are indexed, and in the bibliographical collection of two universities of Ceará, relative to the period of 2000 to 2005.33 articles were analyzed. The results permitted the verification that postgraduation students were more interested in the thematic; $85 \%$ of the studies were arising from of the Southeast of the Country and of the predominance of Qualitative studies (26). We establish also 29 participations of family members in activities of care. In conclusion, the nursing has inserted the family care at home in its researches, however still of incipient way, what shows its inhibited contribution for the preparation of those families for the practical care.

Descriptors: Research; Nursing; Family.

\section{RESUMEN}

El objetivo fue analizar la produccción científica de la enfermería cerca de la temática cuidado familiar en el domicilio, a través del levantamiento bibliográfico en direcciones electrónicas de periódicos de enfermería QUALIS "C " internacional y en el acervo bibliográfico de dos Universidades Cearenses, relativo al período de 2000 hasta 2005. Han sido analisados 33 artículos. Los resultados han permitido la constatación del mayor interés de alumnos de pós-grado por la temática, de lo Que $85 \%$ de los trabajos eran oriundos de Sudeste del país y de la predominancia de estudios cualitativos (26). Hemos constatado también 29 participaciones de miembros familiares en actividades de cuidado. Hemos concluído que la enfermería há inserido el cuidado familiar en el domicilio en sus investigaciones, pero aún de modo incipiente, lo Que retrata su inhibida contribución para el preparo de esos familiares para el cuidado en la práctica.

Descriptores: Investigación; Enfermería; Família. 


\section{INTRODUÇÃO}

O cuidado domiciliário ganha destaque com a mudança no perfil demográfico e epidemiológico da população brasileira, com o aumento da sobrevida humana e a maior ocorrência de doenças crônico-degenerativas. Tal fato implica na existência cada vez maior de idosos dependentes de suas famílias e dos serviços de saúde ${ }^{(1)}$.

Há uma estimativa de Que 10\% da população acima dos 65 anos necessite de auxílio para realizar tarefas como vestir-se, alimentarse, tomar banho, ou seja, executar Atividades da Vida Diárias $(A V D s)^{(1)}$. Dessa forma, a família reassume um papel Que há tempos detém, porém há pouco vem sendo preparada pelos serviços de saúde para exercer, o de ser cuidadora, necessitando de apoio emocional e técnico na execução das atividades desenvolvidas no contexto domiciliar.

Para o cuidado desenvolvido no domicílio, a literatura formulou alguns conceitos, dentre eles, o de cuidado formal, descrito como aQuele promovido por profissionais e o de cuidado informal, como aQuele proporcionado pela família, pelos amigos, vizinhos ou parentes ${ }^{(2)}$. Há ainda a definição dos cuidados para a promoção ou reparação da vida, Que são aQueles Que necessitam de vigilância direta e contínua do profissional de saúde, e os cuidados de manutenção da vida, Que são os realizados pelo cliente ou sua família, sob as orientações de uma equipe multiprofissional de saúde ${ }^{(1)}$.

Sabe-se Que o preparo das famílias, em especial dos cuidadores familiares, pelos profissionais de saúde contribui para o sucesso no seguimento de tratamentos e, conseqüentemente, para uma breve recuperação dos indivíduos. Nesse contexto, a enfermagem apresenta-se como profissão Que participa da capacitação da família para o cuidado, visto Que possui formação voltada à educação da clientela Que assiste.

O cuidado da Enfermagem no domicílio traz à tona além de um cuidado terapêutico, aspectos afetivos e de relação de ajuda ${ }^{(3)}$. Dessa forma, uma vez Que a Enfermagem esteja preparada para exercer esse cuidado, certamente trará valiosas contribuições para uma reestruturação no cenário de doenças crônico-degenerativas Que hoje se apresenta.

A realização desse estudo motiva-se pelo desejo de aprofundar os conhecimentos acerca do cuidado da família no domicílio, destacando a Enfermagem como profissão Que vem desenvolvendo estudos sobre a temática e explorando esse campo em sua prática. Questiona-se, assim, Quem tem produzido, do ponto de vista da titulação, artigos sobre essa temática na enfermagem. Quais as regiões do país estudam mais o tema? Qual a natureza das pesQuisas desenvolvidas e a Qual clientela se destina o cuidado domiciliário estudado pela enfermagem?

Para responder a estes Questionamentos, fez-se um levantamento bibliográfico em periódicos de enfermagem Que abordam a temática. Acredita-se que os achados de tal investigação possam contribuir com o entendimento do assunto, lançando subsídios teóricos para Que o profissional conheça o cuidado realizado no domicílio e possa elaborar estratégias de acompanhamento e aprimoramento dessa modalidade de cuidado.

\section{MÉTODO}

Trata-se de um estudo de revisão da literatura, constituído a partir do levantamento bibliográfico em periódicos de enfermagem QUALIS C Internacional, disponíveis em seus endereços eletrônicos e no acervo das bibliotecas de duas Universidades Cearenses.

$\mathrm{O}$ acesso às fontes de pesquisa ocorreu no período de abril a maio de 2006, totalizando o número de Quatro periódicos, cuja seleção obedeceu aos seguintes critérios de inclusão: acessibilidade, disponibilidade dos números na íntegra e relação com a temática. Foram excluídos os artigos publicados fora do período de interesse da pesquisa e em idioma diferente do português.

Para preservar o anonimato das publicações periódicas Que atendiam aos critérios de seleção propostos, optou-se por identificálos segundo a ordem alfabética que se segue: Periódico A, Periódico B, Periódico C e Periódico D.

A coleta dos dados teve início com a consulta sistemática, via internet, aos endereços eletrônicos dos periódicos A e B, obedecendo aos critérios de inclusão. Em ambos foram encontrados 10 (dez) artigos relacionados à temática. Ressalta-se, porém, Que o periódico B possuía além dos dez, mais três artigos, capturados na sua versão impressa na biblioteca de uma universidade, não disponíveis na versão eletrônica.

A seguir, buscou-se os demais periódicos nas bibliotecas de duas Universidades Cearenses. Dessa busca resultaram dois periódicos, C e D, Que dispunham de todos os números em versão impressa, no período de interesse. Identificados os periódicos, seus sumários foram manuseados em busca de artigos sobre a temática.

Cada um dos periódicos dispunha de cinco artigos relacionados à temática. Os artigos selecionados foram capturados, perfazendo um total de 33 (trinta e três). A partir de então, deu-se início ao fichamento e à organização dos artigos, segundo a fonte, o local de captura e o conteúdo.

Após o fichamento, os artigos foram organizados de acordo com as seguintes variáveis: as titulações e as regiões do País de origem dos autores, os tipos e naturezas dos estudos e o conteúdo dos artigos Quanto ao ser cuidado, ao cuidador e ao ambiente de abordagem das pessoas peseuisadas.

Após analisar o material disponível nos periódicos consultados, foram elaboradas figuras a partir do programa Excel, cujos conteúdos passamos a discutir.

\section{RESULTADOS E DISCUSSÃO}

A análise dos artigos catalogados resultou na construção de figuras Que ilustram as variáveis descritas na metodologia. Os conteúdos das mesmas foram apresentados de forma descritiva, intercalando discussões respaldadas na literatura.

A figura I apresenta a distribuição dos artigos segundo a titulação de seus autores, no período estudado.

Para a construção desta figura, foram considerados trabalhos de mestrado aqueles cujos autores estavam cursando mestrado ou apresentando suas dissertações. Como trabalhos de doutorado, aQueles cujos autores estavam cursando o doutorado ou publicando suas teses. Foram considerados como trabalhos de iniciação científica os Que possuíam como autores alunos de graduação em enfermagem. E como trabalhos de docentes, aqueles cujos autores se identificavam como professores de graduação/pós-graduação de alguma instituição de ensino. 
Observamos maior interesse dos doutorandos pelo estudo da temática, com nove artigos; seguido dos mestrandos e dos docentes, ambos com uma produção de oito artigos. Acreditamos Que os doutorandos e mestrandos apresentam porcentagens significativas de trabalhos, em virtude da importância de tais cursos na formação de pesquisadores, Que desenvolvem a consciência de publicar aquilo Que investigam, a fim de tornar acessível à sociedade o produto de suas construções.

Destacamos os trabalhos de iniciação científica Que apresentaram uma produção de seis artigos. Destes, três trabalhos foram financiados pelo $\mathrm{CNPQ}$, dois pela FAPESP e um pelo Programa de Aprimoramento Discente (PAD) da Universidade Federal de Minas Gerais. Tal fato demonstra a preocupação dos discentes e docentes na publicação de trabalhos ainda na graduação.

Frente à distribuição de artigos em diversos níveis de titulação, interessou-nos também identificar Quais as regiões de origem dos mesmos (Tabela I).

Fica evidente na análise da variável procedência dos autores por região Que a região Sudeste, aqui representada pelos estados de São Paulo e do Rio de Janeiro, responde pelo número de 28 (vinte e oito) artigos acerca da temática. Foi atribuído a tal feito o fato de Que os periódicos com um maior número de artigos são órgãos oficiais de divulgação científica das próprias instituições de ensino superior nas Quais os autores lecionam ou cursam a graduação/pós-graduação.

A região Sul apareceu nas publicações de dois periódicos, com dois artigos em cada. A temática do cuidado domiciliar, portanto, ainda não tem grande representatividade na região, porém já desperta o interesse de alguns pesquisadores. Está em construção o caminho para Que, no futuro, esse Quadro seja transformado, prova disso é a aparição de Quatro artigos nessa região, com reconhecido destaQue nacional em termos de produção científica.

Destaca-se Que a região norte não apresentou artigos. Dados do Ministério da Ciência e Tecnologia (2003) ${ }^{(4)}$ mostram que a região abriga cerca de 70 (setenta) cursos de pós-graduação, representando $2 \%$ do total de cursos do País e 1\% do número de alunos. Destacam, ainda, Que uma das melhores soluções para o desenvolvimento sustentável da região é o investimento na formação de recursos humanos Qualificados por meio da pós-graduação.

Outro aspecto considerado importante na análise das pesQuisas foi a caracterização das mesmas Quanto às suas naturezas, ou seja, Quanto ao fato de serem Quantitativas, Qualitativas ou QuantiQualitativas, segundo a descrição dos autores.

O primeiro ponto a destacar é a maioria dos estudos Qualitativos, 26 (vinte e seis), o Que demonstra um grande interesse dos enfermeiros pelo desenvolvimento de pesquisas dessa natureza. Acreditamos Que a temática investigada contribua para esse tipo de estudo, uma vez Que busca a interpretação ou o conhecimento das vivências da família ou dos cuidadores no processo de cuidar ${ }^{(5)}$.

O segundo ponto é Que, mesmo diante dos aspectos subjetivos relativos à temática, seis autores interessaram-se por explorá-la de maneira Quantitativa, mais especificamente, traçando o perfil demográfico e social dos cuidadores. Esse tipo de estudo tem a simpatia tanto das agências de fomento à pesquisa Quanto dos editores de periódicos. Esse é um ponto de grande discussão entre os enfermeiros pesquisadores Que se dividem entre a produção de pesquisas Qualitativas, Que já possuem um grande número de adeptos, por sua proximidade com o objeto de estudo e de trabalho da enfermagem, o ser humano, e a produção de pesQuisas Quantitativas Que, ao longo do tempo, foram se solidificando como estudos Que permitiam validação estatística e generalização de resultados $^{(6)}$.

Tabela 1. Variáveis analisadas.

\begin{tabular}{|c|c|}
\hline Variáveis & $\mathbf{N}$ \\
\hline \multicolumn{2}{|l|}{ Titulação dos autores } \\
\hline Iniciação Científica & 6 \\
\hline Docentes & 8 \\
\hline Especialização & 2 \\
\hline Mestrado & 8 \\
\hline Doutorado & 9 \\
\hline \multicolumn{2}{|l|}{ Procedência dos Autores por Região } \\
\hline Nordeste & 1 \\
\hline Sudeste & 28 \\
\hline Sul & 4 \\
\hline \multicolumn{2}{|l|}{ Natureza ou Abordagem dos Estudos } \\
\hline Quanti/Quali & 1 \\
\hline Quantitativa & 6 \\
\hline Qualitativa & 26 \\
\hline \multicolumn{2}{|c|}{ Caracterização dos Artigos por Tipo de PesQuisa } \\
\hline Original - Etnográfico & 1 \\
\hline Relato de Experiência & 1 \\
\hline Revisão da Literatura & 1 \\
\hline Original - Descritivo-exploratório & 4 \\
\hline Estudo de Caso & 1 \\
\hline Reflexão & 5 \\
\hline Não identificado & 11 \\
\hline Não referido & 2 \\
\hline
\end{tabular}


Tecidas as considerações sobre a natureza das pesquisas, foram particularizados os tipos de estudos de cada uma delas. Inicialmente, destacam-se como os tipos de estudos Quantitativos: exploratórios, descritivos e exploratório/descritivos, com três, dois e um artigos, respectivamente.

Chamou-nos a atenção o grande número de pesquisas Qualitativas Que não faziam referência à tipologia do estudo. Os autores relataram apenas Que se tratava de um estudo de abordagem Qualitativa, alguns chegavam até a citar os referenciais teóricometodológicos utilizados, mas não especificavam o tipo de estudo. Entre os 26 estudos Qualitativos analisados, 11 apresentavam-se nessas condições. Vê-se, ainda, na figura uma predominância de estudos Qualitativos Que utilizam a reflexão teórica e estudos descritivo-exploratórios.

Destaca-se na figura 1, a clientela estudada pelos autores. É possível observar a caracterização das pessoas cuidadas, dos cuidadores e do ambiente no Qual ocorreu a pesquisa.

Com relação aos seres cuidados, observamos a predominância de portadores de transtorno mental e de idosos. No primeiro caso, saúde e doença mental confundem-se, ou seja, fala-se em saúde mental com destaque às manifestações da doença mental e às dificuldades vivenciadas pelas famílias no convívio com o portador de transtorno mental ${ }^{(7,8)}$. Estudam-se os significados da família diante da vivência com um portador de sofrimento psíquico e as transformações pelas Quais as famílias passam ao longo do tempo Quando se fala em estigma e em cuidar do indivíduo no próprio domicílio( $^{(9,10)}$.

Acredita-se Que a presença de um grande número de estudos sobre saúde do idoso deu-se em virtude do momento de transição demográfica pelo eual a sociedade vem passando. Temos uma população crescente de idosos e serviços de saúde Que não acompanham esse crescimento no mesmo passo. Observa-se, ainda, um aumento na freeüência de doenças crônico-degenerativas Que, por sua vez, são mais presentes na população idosa ${ }^{(11,12)}$.

Quando se destaca o cuidador, percebe-se a distinção entre duas categorias: o cuidador formal e o informal. Como definidos no início do trabalho, os primeiros apresentam-se como profissionais, com capacitação específica, contratados para o exercício das atividades de cuidado domiciliares, enQuanto os informais pertencem à família, ou à rede de amigos e vizinhos da pessoa cuidada e Que não possuem formação profissional(2).

De fato, os cuidadores informais aparecem em maioria - 31 vezes. Percebe-se, portanto, Que Quando o cuidado é realizado em âmbito domiciliar há um predomínio de cuidadores da própria família, mesmo sem a capacitação técnica necessária para as atividades.

Quanto aos ambientes nos Quais se desenrolaram as pesQuisas, encontramos o domicílio em 12 (doze) aparições, número Que vai ao encontro da temática. Destacamos o aparecimento de trabalhos realizados em unidades hospitalares (três deles), pois demonstra a preocupação dos profissionais desse setor com a alta hospitalar do paciente, instituindo ações de escuta e de acompanhamento à família. Considera-se essa atitude importante, uma vez que o restabelecimento de um indivíduo após uma internação deve-se muito à atenção, ao cuidado ou à participação dos familiares.

O ambiente ambulatorial apresenta-se também de forma expressiva, em nove pesquisas. As mesmas foram realizadas nos momentos em Que um familiar cuidador acompanhava a pessoa cuidada a uma consulta ou seguimento ambulatorial. Há ainda um estudo feito em uma casa de apoio e dois Que utilizaram a entrevista por telefone como forma de contato.

Por fim, encontramos seis estudos Que não foram desenvolvidos em ambientes específicos. Trata-se de cinco reflexões teóricas e uma revisão de literatura ou estudo bibliográfico. Essas pesquisas discutiram a participação da família, principalmente, no acompanhamento aos portadores de transtornos mentais. Fizeram uma retrospectiva histórica da percepção da família como cuidadora,

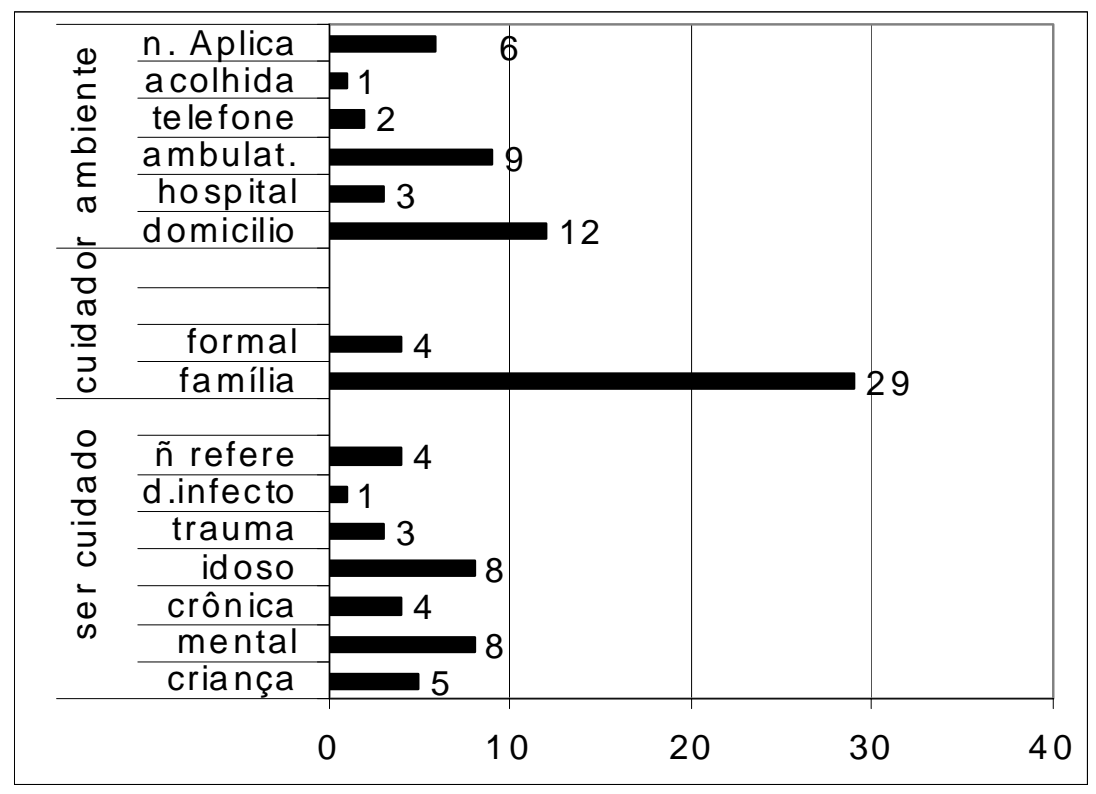

Figura 1. Clientela abordada nas peseuisas. 
assim como dos mecanismos desenvolvidos para o enfrentamento dos estigmas associados à condição da pessoa cuidada.

\section{CONSIDERAÇÕES FINAIS}

O trabalho permitiu a identificação do interesse da enfermagem pela temática, revelando-se mais intenso nos trabalhos oriundos dos cursos de pós-graduação, em especial dos mestrandos e doutorandos.

Essa pesquisa levou-nos ao Questionamento sobre Quais as dificuldades dos enfermeiros pesquisadores das regiões Norte e Nordeste para publicar suas produções. Ao voltar nosso pensamento para a graduação, nos Questionamos sobre os estímulos que nos foram oferecidos para o desenvolvimento e a publicação de nossos trabalhos.
Pensamos Que ainda há tempo para transformar o panorama Que se apresenta, mas sabemos Que sem recursos e profissionais Qualificados e interessados essa tarefa torna-se mais árdua.

$\mathrm{O}$ Que dizer das pesquisas Qualitativas predominantes na enfermagem? O Que se sabe é da consciência dos enfermeiros Quanto ao seu objeto de estudo. São pessoas cuidando de outras pessoas e isso se reflete nos trabalhos, nos objetos de investigação e nas condutas do profissional em sua assistência.

Considera-se Que este trabalho destacou a enfermagem como profissão Que procura aprimorar o seu fazer baseando-se no conhecimento científico Que produz e no cotidiano de suas ações de cuidado. Espera-se com o mesmo oferecer um olhar diferenciado às pesQuisas da enfermagem, destacando a necessidade de maiores estímulos à sua publicação.

\section{REFERÊNCIAS}

I. Klock AD, Heck RM, Casarim ST. Cuidado domiciliar: a experiência da residência multiprofissional em saúde da família/ UFPEL-MS/BID. Texto Contexto Enferm 2005; I4(2): $237-$ 45.

2. Benjumea CC. Cuidado familiar en condiciones crónicas: una aproximación a la literatura. Texto Contexto Enferm 2004; 13 (I): 137-46.

3. Lacerda MR. Tornando-se profissional no contexto domiciliar - vivência do cuidado da enfermeira [tese]. Florianópolis (SC): Programa de Pós-Graduação em Enfermagem/UFSC; 2002.

4. Ministério Ciência e Tecnologia (BR). Agência CT. [citado em: 16 jun 2006]. Disponível em: URL: http://agenciact.mct.gov.br/ index.php/content/view/l 4391.html

5. Nascimento LC, Rocha SMM, Hayes VH, Lima RAG. Crianças com câncer e suas famílias. Rev Esc Enferm USP 2005; 39(4): 469-74.

6. Minayo MC, Sanches O. Quantitativo-Qualitativo: oposição ou complementaridade? Cad Saúde Pública 1993; 9(3): 239-48.
7. Catena RM, Galera SAF. Doente mental e família: estes desconhecidos. Acta Paul Enferm 2002; 15(I): 53-8.

8. Moreno V, Alencastre MB. A trajetória da família do portador de sofrimento psíquico. Rev Esc Enfern USP 2003; 37(2): 43-50.

9. Fugerato ARF, Santos OS, Nievas AF, Silva EC. O fardo e as estratégias da família na convivência com o portador de doença mental. Texto Contexto Enferm 2002; 1 I (3): 5 1 -6.

10. Colvero LA, Ide CAC, Rolim MA. Família e doença mental: a difícil convivência com a diferença. Rev Esc Enferm USP 2004; 38(2): 197-205.

11. Rodrigues MR, Brêtas ACP. O Significado da assistência domiciliária para o idoso e/ou seu cuidador familiar matriculados em um programa público de assistência domiciliária ao idoso. Acta Paul. Enf. 2002; 1 5(3): 60-71.

12. Kawasaki K, Diogo MJD. Assistência domiciliária ao idoso: perfil do cuidador formal - Parte I. Rev Esc Enferm USP 200I; 35(3): 257-64. 